is that although the authors encourage contact with specialist mental health services, the section on the role of the psychiatrist is next to that on compulsory detention in hospital.

The authors try hard to engage a wide audience and the book is more likely to be read by some patients and their families than others. The families of those with severe mental illness will find this book helpful but it is unlikely to be read by the patients who may have been hospitalised for many years. It will be a useful resource for junior doctors who often have theoretical knowledge of cognitive approaches in psychosis but have very little practical experience. They would particularly benefit from the clear advice that families do not cause schizophrenia. Moreover, it is likely to be helpful for those within the voluntary and charitable sector, those involved in residential care and members of assertive outreach and community mental health teams.

columns

\title{
miscellany
}

\section{Request for information}

I am funded by the Economic and Social Research Council and am researching for a $\mathrm{PhD}$ on 'Homosexuality and military authority in the British Armed Forces, 1939-1945'. Principally, I am interested in exploring the experiences of gay and lesbian service personnel during the Second World War. However, part of my research examines medical, social and military understanding of homosexuality and lesbianism in the 1940s. Therefore, I would like to correspond with or interview medical personnel who practised or served during the Second World War. I would like to hear from anybody who encountered or treated homosexual service personnel inside and outside of the Armed Forces in that period or from anybody who served on a medical board. I would also be interested to hear from anybody who could contribute references to sources or offer any further leads. Complete confidentiality is assured. Please contact: Ms Emma Vickers, Department of History, Furness College, University of Lancaster, Lancaster, LA1 4YG (email e.vickers@ lancaster.ac.uk).

\section{forthcoming events}

The Royal Society of Medicine, Wessex Region are the organisers of a 1-day conference entitled Children with special needs - coordinating education, health and social care which will take place on Thursday 14 September 2006 at the Lees Lecture Theatre, Talbot Campus, Bournemouth University, Poole. This conference will explore ways in which children's agencies could collaborate to ensure that physical and mental difficulties are identified at an early stage. Proposals for adopting optimum care and educational strategies for children and parents will also be discussed. For further information please contact Mr Simon Timmis, Royal Society of Medicine, 1 Wimpole Street, London W1G OAE (tel: +44 20 7290 3844; fax: +44 207290 2977; email: simon.timmis@rsm.ac.uk).

The University of Birmingham, in conjunction with the Learning Disability Faculty and the Research and Training Unit of the Royal College of Psychiatrists, and MENCAP have produced a new national guideline on The use of medication for

\section{the management of behaviour} problems among adults who have learning disability. To introduce this guideline, which contains a number of good practice points that aim to improve the quality of care and endorse health gain for adults with learning disability, a series of free nationwide conferences will be held in 2006. Locations and dates are as follows: Birmingham (4 September), Glasgow (11 September), Newcastle (18 September), Liverpool (25 September), London (9 October), Bristol (16 October) and London (23 October). Conference attendance is free but places are limited so booking should be made in advance. For further information please visit http:// www.ld-medication.bham.ac.uk. For information or to book a place please contact Jarvey Moss at the University of Birmingham (tel: 0121678 2364; fax: 0121 6782351; email: psychiatry-admin@ lists.bham.ac.uk).

The 15th European Congress of Psychiatry will take place in Madrid, Spain on 17-21 March 2007. The deadline for submission of abstracts is 15 November 2006. For further information please visit http://www.kenes.com/ aep2007 or contact the organisers at 15th European Congress of Psychiatry, Kenes International Global Congress Organisers and Association Management Services, 17 Rue du Cendrier, PO Box 1726 CH-1211 Geneva 1, Switzerland (tel: +41 22908 0488; fax: +41 22732 2850; email: aep2007@kenes.com).

St George's University of London (Department of Mental Health, Learning Disability) would like to announce the following 1-day event which is taking place on 27 September 2006 at St George's: Psychiatric education. Undergraduate to postgraduate: the evolving future. Places are free but those attending must register. For further information and registration please visit http://www.sgul.ac.uk/depts/psychdis/ psyched.htm.

\section{corrigendum}

The email addresses given

for Drs Harvey Gordon, Peter Cornwal

and Ajay Vijayakrishnan in the correspondence of the August issue (Psychiatric Bulletin, 30, 313-314) were incorrect. The correct addresses are Anna.Kennedy@obmh.nhs.uk lenny.cornwall@tney.northy.nhs.uk and avijayak@sgul.ac.uk respectively. 